\title{
Nanocomposite sensors of propylene glycol, dimethylformamide and formaldehyde vapors
}

\author{
Zaven Adamyan ${ }^{1}$, Artak Sayunts ${ }^{1}$, Vladimir Aroutiounian ${ }^{1}$, Emma Khachaturyan $^{1}$, Martin Vrnata $^{2}$, \\ Přemysl Fitl ${ }^{2}$, and Jan Vlček ${ }^{2}$ \\ ${ }^{1}$ Department of Physics of Semiconductors and Microelectronics, Center of Semiconductor Devices \\ and Nanotechnologies, Yerevan State University, 1 A. Manoukian, 0025 Yerevan, Armenia \\ ${ }^{2}$ Department of Physics and Measurement Technology, University of Chemistry and Technology, \\ Technická 5, 16628 Prague 6, Czech Republic
}

Correspondence: Artak Sayunts (sayuntsartak@ysu.am)

Received: 28 September 2017 - Revised: 13 December 2017 - Accepted: 27 December 2017 - Published: 1 February 2018

\begin{abstract}
The results of research works related to the study of thick-film multiwall carbon nanotube-tin oxide nanocomposite sensors of propylene glycol (PG), dimethylformamide (DMF) and formaldehyde (FA) vapors are presented in this paper. These sensors were derived using hydrothermal synthesis and sol-gel methods. Investigations of response-recovery characteristics in the $50-300{ }^{\circ} \mathrm{C}$ operating temperature range reveal that the optimal operating temperature for PG, DMF and FA vapor sensors, taking into account both high response and acceptable response and recovery times are about 200 and $220^{\circ} \mathrm{C}$, respectively. The dependence of the sensor response on gas concentration is linear in all cases. Minimal propylene glycol, dimethylformamide and formaldehyde gas concentrations, where the perceptible signal was noticed, were 13, 5 and $115 \mathrm{ppm}$, respectively.
\end{abstract}

\section{Introduction}

There are various harmful and hazardous matter vapors, which have a major role in diverse spheres such as environmental protection, industrial manufacturing, medicine and national defence. As an illustration, propylene glycol (PG) is an excellent solvent for many organic compounds and is used as an active ingredient in engine coolants and antifreeze, brakes, paints, enamels and varnishes, and also as a solvent or surfactant in many products. It also can be found in cosmetics, perfumes and pharmaceuticals.

Another example is dimethylformamide (DMF) which is used as a solvent in vinyl resins, adhesives, pesticide and epoxy formulations. It purifies and separates acetylene, 1,3butadiene, acid gases and aliphatic hydrocarbons. DMF is also used in the production of polyacrylic or cellulose triacetate fibres and pharmaceuticals or in the production of polyurethane resin for synthetic leather (Fiorito et al., 1997).

Formaldehyde (FA) is a colorless, water-soluble gas with a pungent odor, which used in making building materials and in many household products such as particleboard, plywood and fiberboard, glues and adhesives, textiles, papers and their product coatings. Besides, formaldehyde can serve an intermediate product in the manufacture of industrial chemicals. It can also be found as a preservative substance in some foods and products, such as antiseptics, medicines and cosmetics (Lefebvre et al., 2012).

DMF, PG and FA have a huge impact on human organs (e.g. liver, skin, eyes and kidneys) (Fiorito et al., 1997; Lefebvre et al., 2012; Malaguarnera et al., 2012; Chang et al., 2004). PG can cause nausea and vomiting, headaches, dizziness and fainting. Moreover, it is known as a combustible liquid, which can explode in fire. A minimal risk level of $0.009 \mathrm{ppm}$ has been derived for constant-duration (15364 days) inhalation exposure to propylene glycol (Robertson et al., 1947). FA gas can cause burning sensations in the eyes, nose and throat as well as cause coughing, wheezing, nausea and skin irritation. Besides, exposure to relatively high amounts of formaldehyde can increase the risk of leukemia and even cause some types of cancer in humans. The United States Occupational Safety and Health Administration (OSHA) has set its short-term exposure limit (15$30 \mathrm{~min}$ ) at $2 \mathrm{ppm}$ and permissible exposure limit (up to $8 \mathrm{~h}$ ) 
to $0.75 \mathrm{ppm}$ (Salthammer et al., 2010). The current OSHA standard for dimethylformamide is $10 \mathrm{ppm}$ averaged over an $8 \mathrm{~h}$ work shift (Ellenhorn, 1997).

Due to the information noted above, PG, DMF and FA gas sensors are commonly applied for detecting and continuously monitoring these gases in the spheres where they are used.

Despite our careful analysis of data in the literature, we did not find any works related to research on and development of resistive-type sensors for PG and DMF gases. There are only studies on sensors working on other principles (for example, sensors working on a modification of the color of the substance), which is incompatible with modern techniques, while resistive gas sensors, made from metal oxides, have some advantages such as availability of the electric signal, measurement of gas concentration, small sizes, low power consumption, high sensitivity and high reliability (Fine et al., 2010; Korotcenkov et al., 2013). As opposed to this case, there are various types of FA gas sensors: for instance, FA gas sensors based on graphene or polymers, which are working at a room temperature (Chuang et al., 2015; Flueckiger et al., 2009). However, FA gas sensors, which are based on metal-oxide materials, have benefits that are mentioned above. Meanwhile, pure metal oxide structures react on FA at higher operating temperatures $\left(300-400{ }^{\circ} \mathrm{C}\right)(\mathrm{Xu}$ et al., 2014; Park et al., 2014) or room temperature with the assistance of UV LEDs (Chung et al., 2014; Li et al., 2015).

Nanomaterials, such as carbon nanotubes (CNTs), metaloxide nanoparticles, nanotubes, nanowires and other various nanopattern formations are widely used in gas sensing structures due to their excellent responsive characteristics, mature preparation technology and low cost of mass production (Aroutiounian, 2015; Arafat et al., 2012; Korotcenkov et al., 2009; Aroutiounian et al., 2013; Feyzabad et al., 2012; Hieu et al., 2008). When CNTs' walls are covered with metal-oxide nanoparticles, the specific surface area of sensitive gas material enlarges. Furthermore, nanochannels in the form of hollows of CNTs promote penetration of gas molecules deeper down in the nanocomposite sensitive layer (Bai et al., 2014). Hence, it can be expected that application of nanocomposite structures composed of metal oxide functionalized with CNTs in the technology of gas sensors should improve gas sensor parameters, such as gas response, response, recovery times and operating temperature.

Our recent works related to the study of gas sensors based on multiwall carbon nanotubes/tin oxide $\left(\mathrm{MWCNTs} / \mathrm{SnO}_{2}\right)$ nanostructures are also supported by Aroutiounian et al. (2013, 2015) and Adamyan et al. (2016). The choice of tin-oxide as a component of $\mathrm{SnO}_{2} / \mathrm{MWCNT}$ nanocomposite structure is conditioned by the fact that $\mathrm{SnO}_{2}$ is a well-known basic material for metal-oxide gas sensors (Korotcenkov et al., 2009; Aroutiounian, 2007; Shankar et al., 2015). We expected that coating of functionalized MWCNTs with $\mathrm{SnO}_{2}$ nanoparticles with admissible (close to double Debye length) sizes (Xu et al., 1991; Adamyan et al., 2003, 2007) should provide the improved performance of the gas sensor and lower its operating temperature.

Here, we present the characteristics of the PG, DMF and FA vapor sensors based on ruthenated thick films of $\mathrm{MWCNT} / \mathrm{SnO}_{2}$ nanocomposite structures. The choice of corresponding processing technique, treating conditions and regimes for CNTs functionalization, as well as the modification of thick films surface with Ru catalyst, are described below in Sect. 2. Results of the measurements of PG, DMF and FA vapor sensors and their discussions are given in Sect.3.

\section{Materials and methods}

\subsection{Materials preparation}

MWCNT membranes, which were used for the preparation of nanocrystalline MWCNTs/ $\mathrm{SnO}_{2}$ powder, were kindly provided to us by our colleagues from the University of Szeged, Hungary. MWCNTs were prepared by the decomposition of acetylene (CVD method) using a $\mathrm{Fe}, \mathrm{Co} / \mathrm{CaCO}_{3}$ catalyst (Couteau et al., 2003; Magrez et al., 2010). This growth procedure using a $\mathrm{CaCO}_{3}$ catalyst enables a highly efficient selective formation of clean MWCNTs, suitable for efficient bonding between CNT and metal oxide, particularly for $\mathrm{SnO}_{2}$ precursors.

For functionalization of nanotube walls with oxygencontaining hydroxyl $(\mathrm{OH})$, carbonyl $(\mathrm{C}=\mathrm{O})$ and carboxylic $(\mathrm{COOH})$ functional groups, MWCNTs from the membranes were transferred to slurry in $\mathrm{HNO}_{3} / \mathrm{H}_{2} \mathrm{SO}_{4}$ acid mixture over the course of 1 . Such functionalization of the CNTs is vital for the following synthesis of $\mathrm{SnO}_{2}$ nanoparticles on the MWCNT walls since these oxygen-containing groups act as sites for the nucleation of nanoparticles. After rinsing with distilled water and drying at $80^{\circ} \mathrm{C}$, MWCNTs were poured and treated in deionized water in the ultrasonic bath for 5 min.

The preparation of nanocomposite materials with a hydrothermal method was carried out in two steps. Firstly, purified MWCNTs were dispersed in water via sonication. Then, a calculated amount of precursor of the $\mathrm{SnCl}_{2} \cdot 2 \mathrm{H}_{2}$ was dissolved in another beaker in water, after which $3 \mathrm{~cm}^{3} \mathrm{HCl}$ was added to the solution. The choice of water as a solvent, instead of ethanol for example, is connected with the expectation to improve gas sensing characteristics (Nemeth et al., 2014b). In the next step, the MWCNT's suspension and the solution of the precursor were mixed and sonicated for $30 \mathrm{~min}$. To prepare the nanocomposites, we poured solutions mentioned above into autoclaves, where hydrothermal synthesis was carried out at $150{ }^{\circ} \mathrm{C}$ for 1 day. At the end of this procedure, all obtained nanocomposite powders were filtered and dried at $90^{\circ} \mathrm{C}$ for $5 \mathrm{~h}$. The final mass ratio of the nanocomposite MWCNTs/SnO 2 obtained with the hydrothermal method in this study was $1: 200$. The hydrothermal synthesis process is presented in detail again in articles 
mentioned above (Aroutiounian et al., 2013, 2014; Nemeth et al., 2014a).

The paste for the thick film deposition made by mixing powders with $\alpha$-terpineol (Sigma Aldrich) and methanol was printed on the chemically treated surface of the alumina substrate over the ready-made Pt interdigitated electrodes. The thin-film Pt heater was formed on the back of the substrate. Then, the obtained composite structures were cut into $3 \mathrm{~mm} \times 3 \mathrm{~mm}$ pieces. After that, the drying and annealing processes of the resulting thick films were carried out in two stages: the first step is the heating of thick films up to $220^{\circ} \mathrm{C}$ with the $2{ }^{\circ} \mathrm{C} \mathrm{min}^{-1}$ rate of temperature rise, holding for $3 \mathrm{~h}$ and then increasing in temperature to (but not including) $400^{\circ} \mathrm{C}$ with the $1^{\circ} \mathrm{C} \mathrm{min}^{-1}$ rate and holding for $3 \mathrm{~h}$. In the second step, the thick-film specimens were cooled down as the oven cooled.

After annealing and cooling processes, the surface of MWCNTs $/ \mathrm{SnO}_{2}$ thick films was ruthenated by dipping samples into the $0.01 \mathrm{M} \mathrm{RuOHCl}_{3}$ aqueous solution for $20 \mathrm{~min}$, after which they were dried at $80^{\circ} \mathrm{C}$ for $30 \mathrm{~min}$. Then, the annealing treatment was carried out again by the same method noticed above. The choice of the ruthenium as a catalyst was determined by the advantages outlined in Aroutiounian et al. $(2013,2014)$ and Adamyan et al. (2016). At the final stage, ruthenated $\mathrm{MWCNT} / \mathrm{SnO}_{2}$ chips were arranged in TO5 packages, and the gas sensors would be ready for measurements after the bonding of leads.

\subsection{Material characterization}

The morphologies of the prepared $\mathrm{SnO}_{2} / \mathrm{MWCNT}$ nanocomposite powders with diverse compounds were studied by scanning electron microscopy using a Hitachi S-4700 Type II FE-SEM equipped with a cold field emission gun operating in the range of $5-15 \mathrm{kV}$. The presence of an oxide layer was confirmed by SEM-EDX. Furthermore, the crystalline structure of the inorganic layer was also studied by an X-ray diffraction method using the Rigaku Miniflex II diffractometer (angle range: $2 \theta=10-80^{\circ}$, utilizing characteristic X-ray $(\mathrm{CuK} \alpha)$ radiation). Results of these investigations were presented in detail in the Aroutiounian's articles (Aroutiounian et al., 2013, 2014). Here, we are only noting that the average crystalline size of $\mathrm{SnO}_{2}$ nanoparticles, estimated from SEM images and XRD patterns, is less than $12 \mathrm{~nm}$, but the average diameter of non-covered $\mathrm{SnO}_{2}$ nanoparticles CNTs was about $40 \mathrm{~nm}$.

\section{Results and discussions}

Some results of the nanocomposite sensors have been presented during the international conference in Nuremberg (Adamyan et al., 2017). In this paper, we introduce the extended version of our investigations (surface morphology studies, as well as characteristics of a gas sensor), but the performances of PG, DMF and FA sensors are discussed sep-

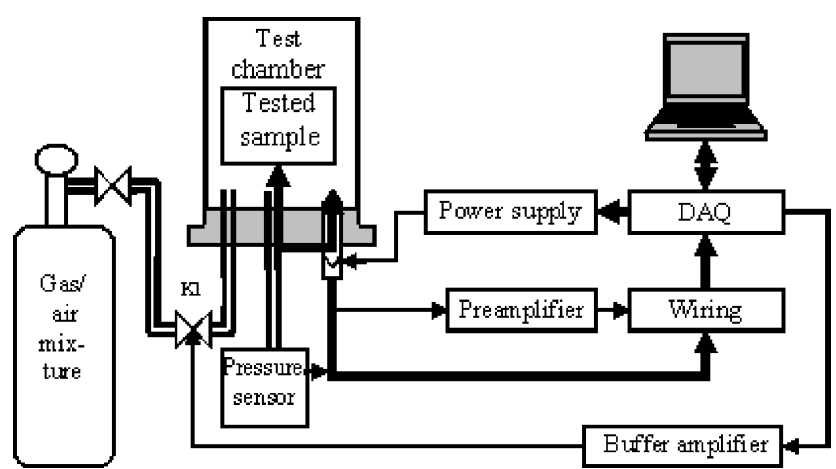

Figure 1. Automated gas-sensor parameter-measurement system flowchart.

arately. Also, the dependence of electrical resistance of the sensors on operating temperature, as well as values of responses, response and recovery times of the sensors at various operating temperatures or target gas concentrations, is shown here.

\subsection{Measurement method}

In order to measure the testing of the semiconductor gas sensors' performances and parameters in the real-time mode faster and more reliably, we developed a similar automated measurement setup. The presence of such a measurement setup with automated DAQ system facilities makes the search of the sensor's optimal operation regime and the action of receiving reliable data about the experiment more accessible.

The developed automated setup leads to measure resistive type gas sensor parameters and allows to display the changes of the resistance of the sensor, which are taking place as a result of fast-acting processes $(\sim 0.1 \mathrm{~s})$ as well as possible long-term drifts. By using this setup, it is possible to get the reliable information about all parameters of the investigated sensors (sensitivity, response and recovery times, sensor's operation temperature, etc.).

The system flowchart in Fig. 1 shows the electromagnetic valve $\mathrm{K} 1$ with the limited-flow faucet as well as the MPX5010DP Motorola pressure sensor connected to the test chamber by leakless passage. The valve control is fulfilled via one of the digital outputs of a PCL-818HG data acquisition (DAQ) card. Connection of the power supply to the sensor's electrodes and heater as well as outputting of the electric signals from the testing specimen is ensured by utilizing the hermetic power socket. The signals proceed to the DAQ card through the PCLD-8115 wiring terminal board. The software control gives the possibility to change the composition, temperature and gas pressure as well as to tune the investigated sensors' surface temperature. The channel of the sensors resistance measurements connects to the DAQ card via a buffer preamplifier. This ensured the size of the resistance and its change over time in the full range of the resis- 


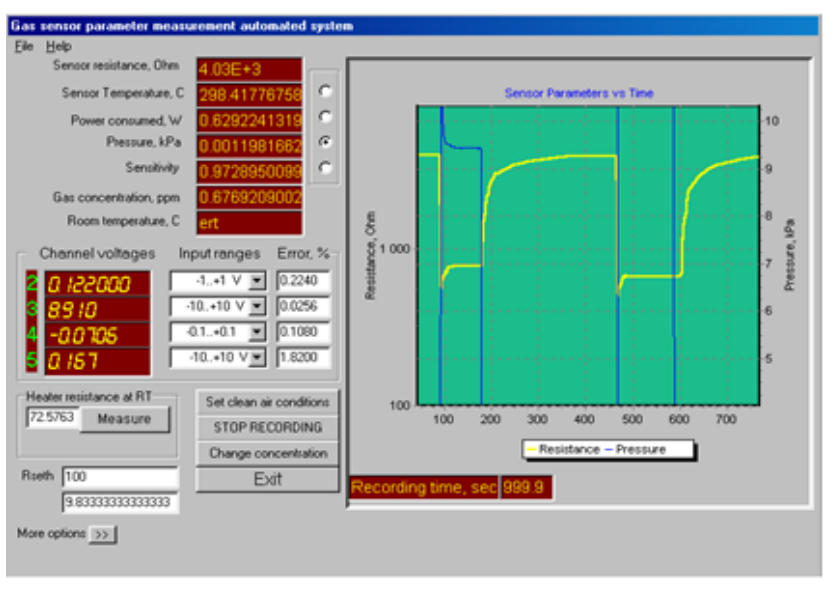

Figure 2. The window of the control program.

tance values from 10 to $1012 \Omega$ with sufficient accuracy. The software ensures an automatic adjustment of the measured resistances and time intervals depending on the entrance of the sensor signal. The interface of software control allows automatical control of the environment of the test chamber (letting the flow of a necessary amount of gas or gas mixture into the chamber). The pressure sensor is providing the flow of the required amount of gas concentration into the chamber.

The operation temperature is maintained by connection of the electric voltage to the thin-film resistive heater of the sensor by the power supply through the DAQ card. The temperature is controlled by the heater resistance measurements with additional recalculations, taking into account the temperature efficiency of the heater material. The monitor screen displays any of the real-time measured parameters, both in digital and graphical forms, which makes the measurement process transparent and provides the information for interpreting the measurements. Simultaneously, all received data are written to an Excel file as a table. The window of the program's measurements is shown in Fig. 2.

Gas sensing properties of the MWCNTs/SnO ${ }_{2}$ nanocomposite structures were measured by an in-house-developed and computer-controlled static gas sensor test system (Adamyan et al., 2007). The sensors were reheated and studied at different operating temperatures. When the electrical resistance of all studied sensors was stable, the necessary assigned amount of compound in the liquid state for testing sensors was injected by a microsyringe into the measurement chamber. Moreover, the target matter was introduced into the chamber on the special hot plate designed for the quick conversion of the liquid substance to its gas phase. After its resistance reached a new constant value, the test chamber was opened to recover the sensors in the air.

The measurement chamber with the large volume (45 L) was used in this work in order to avoid possible vapor condensation on the chamber walls. The temperature of the gas environment within the chamber was kept near room temperature and controlled by the thermocouple with digital output.

Thus, the possibility of the developed softwareprogrammable automatic setup for gas sensor parameters measurements allows the following conditions to be met:

- PC control of the electromagnetic valve for generation of gas mixtures

- GAS sensor data acquisition and logging

- on-screen monitoring of the station

- monitoring of the gas composition in real time in parts per million (ppm)

- tracking of the sensor response in real time

- robustness allowing measurements spanning months

- the different artificial atmosphere variations during a measurement

- a graphically improved user interface

- monitoring of the operating temperature or voltage applied by the heater (utilizing the developed-softwarecontrolled power supply)

- possibility of controlling the statistical error of the measurements in real time

- on-screen monitoring of the surrounding temperature value

- on-screen tracking of the total gas pressure within the measurement chamber.

A schematic circuit diagram of the apparatus and its parameters is presented in Adamyan et al. (2007).

The primary measurement circuit, similar to those used by many manufacturers, is elementary. Generally speaking, the sensor requires two voltage inputs: heater voltage $(\mathrm{VH})$ and circuit voltage (VC). The VH is applied to the integrated thinfilm heater. Circuit voltage is applied to the voltage divider consisting of the resistance of the sensor and the load resistance connected in series. In our case, standard power supply $(5.0 \pm 0.2 \mathrm{~V} \mathrm{DC}$ or $\mathrm{AC})$ is used for both $\mathrm{VC}$ and $\mathrm{VH}$ to fulfil the sensor's electrical requirements. Heater resistance $(\mathrm{RH})$ is about $73 \Omega$ at room temperature. At that, heater current is $63 \mathrm{~mA}$. Heater power consumption is approximately $315 \mathrm{~mW}$.

\subsection{Gas sensing characteristics}

The sensing characteristics were studied in the $20-300^{\circ} \mathrm{C}$ operating temperature range, and the gas response of the sensors determines $R_{\mathrm{a}} / R_{\mathrm{g}}$, where $R_{\mathrm{a}}$ and $R_{\mathrm{g}}$ are the electrical resistance in the air and target gas-air atmosphere, 


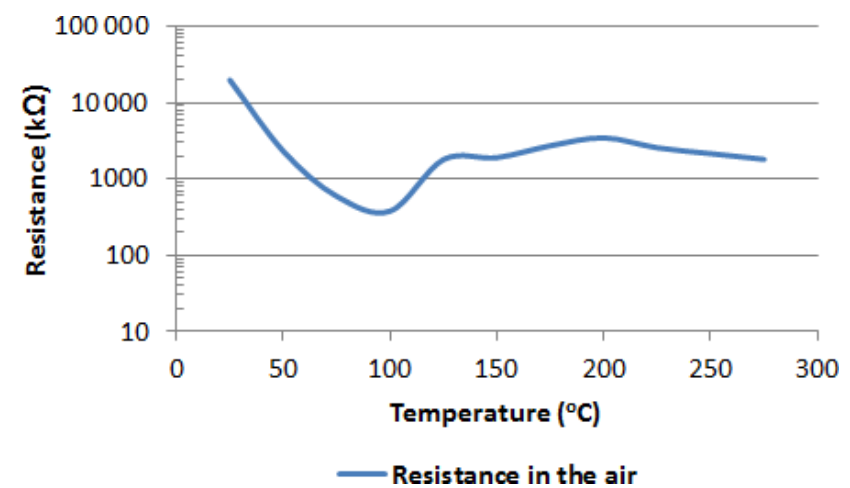

Figure 3. Dependence of electrical resistance change in MWCNTs $/ \mathrm{SnO}_{2}$ sensors on operating temperature in the air.

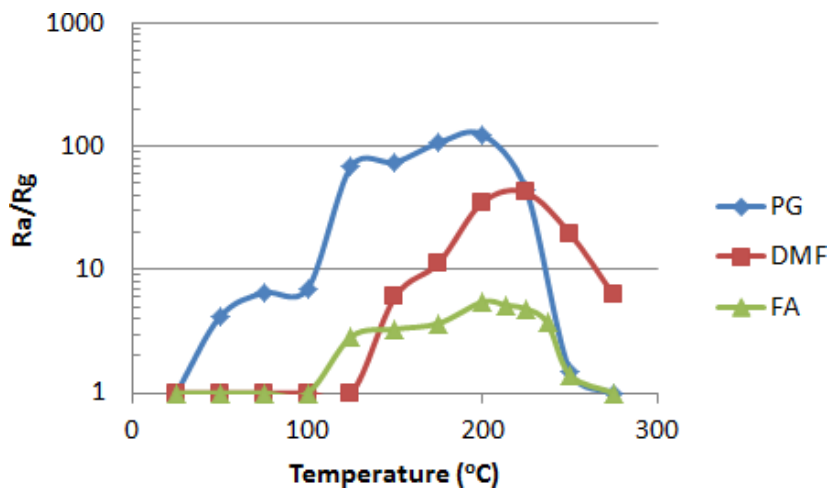

Figure 4. Response vs. operating temperature at $650 \mathrm{ppm} \mathrm{PG}$, 500 ppm DMF and 1160 ppm FA vapor exposure.

respectively. The response and recovery times are determined when the time required for reaching the $90 \%$ resistance changes from the corresponding steady-state value of each signal. Dependence of electrical resistance change in MWCNTs $/ \mathrm{SnO}_{2}$ structures on operating temperature measured in air at $50 \%$ RH is shown in Fig. 3.

\subsection{PG, DMF and FA vapor sensor characteristics}

As a result of measurements of the sensor resistance in air and an air-gas environment, the maximal response to $650 \mathrm{ppm}$ PG vapor was revealed at $200^{\circ} \mathrm{C}$ operating temperature (Fig. 4). Dependence of the response of the sensor on operating temperature in the presence of $500 \mathrm{ppm}$ DMF and 1160 ppm FA vapors in the air are also presented in Fig. 4. As demonstrated, the maximal response to FA and DMF vapors are revealed to be in the range of $200-225^{\circ} \mathrm{C}$ operating temperatures.

Changes in the resistance of the structure depending on PG and FA gas concentrations are presented in Figs. 5 and 6, respectively. Dependence of the response of MWCNTs $/ \mathrm{SnO}_{2}$ sensors on PG, DMF and FA vapor concentration are shown in Figs. 7 and 8, respectively. As it is obvious from the fig-

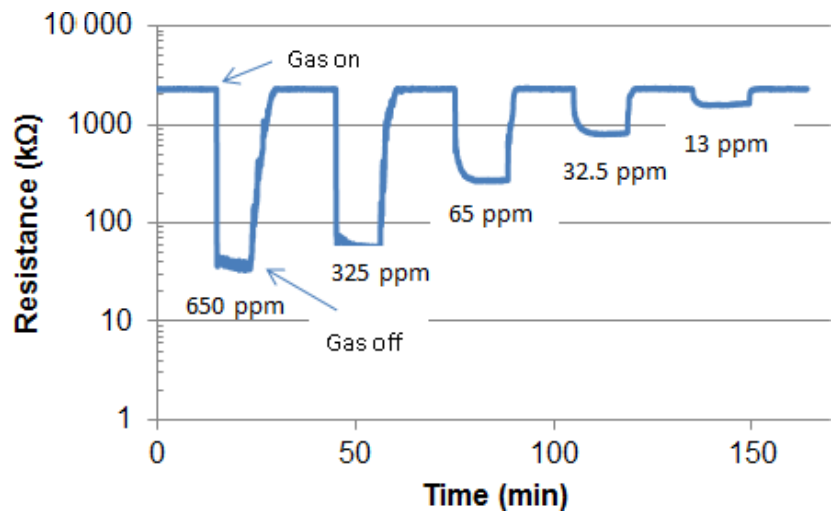

Figure 5. The response-recovery curves observed at different PG concentrations measured at $200^{\circ} \mathrm{C}$ operating temperature.

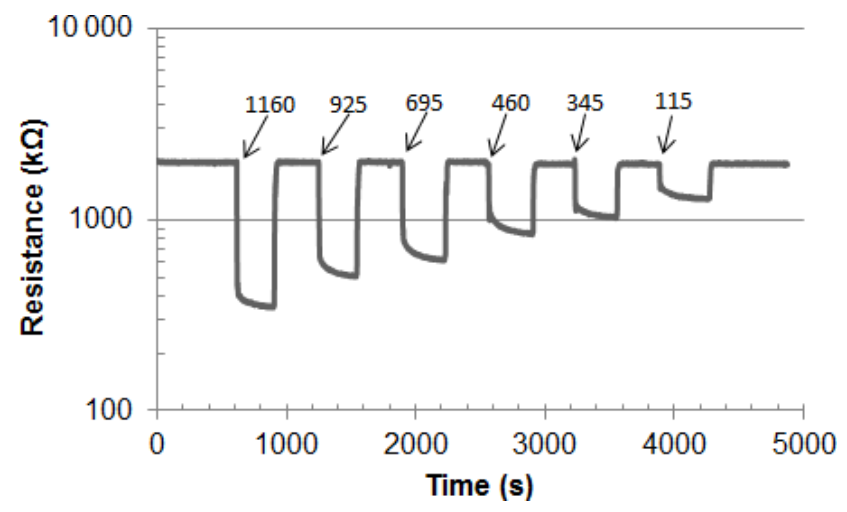

Figure 6. The response-recovery curves observed at different FA concentrations measured at $200^{\circ} \mathrm{C}$ operating temperature.

ures, the sensor response occurs down to small target gas concentrations (13 ppm of PG and $5 \mathrm{ppm}$ of DMF) and the response depends approximately linearly (on a double logarithmic scale in Fig. 7 and in a half logarithmic scale in Fig. 8) on the gas concentration in all cases.

Good repeatability of the sensor response can be seen from Fig. 9, where the electrical resistance change in PG sensor vs. time measured upon cyclic exposure of 650 ppm PG vapors in air at $200^{\circ} \mathrm{C}$ operating temperature is presented.

Changes in the response and recovery times of the sensors depending on PG, DMF and FA vapor concentration are presented in Figs. 10, 11 and 12, respectively.

Changes in the response and recovery times of the PG and FA vapor sensors depending on operating temperature are presented in Figs. 13, 14 and 15. Comparison of responses of MWCNTs $/ \mathrm{SnO}_{2}$ sensors to $650 \mathrm{ppm}$ PG, $500 \mathrm{ppm}$ DMF and $1160 \mathrm{ppm}$ FA vapor exposure vs. operating temperature is shown in Fig. 16.

As shown in Fig. 16, sensors demonstrate the best response against PG and FA vapors at $200^{\circ} \mathrm{C}$ operating temperature and against DMF vapor at $225^{\circ} \mathrm{C}$ operating temperature. 


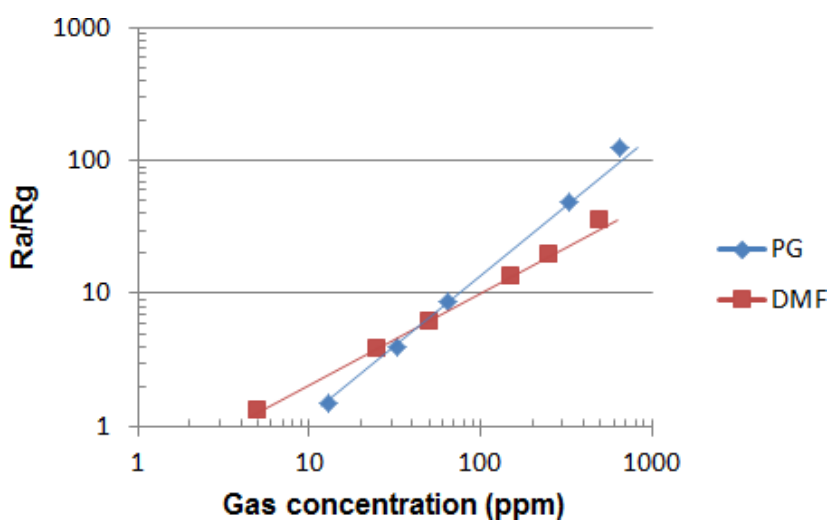

Figure 7. Dependence of the response of $\mathrm{MWCNTs} / \mathrm{SnO}_{2} \mathrm{PG}$ and DMF vapor sensor on gas concentration measured at $200^{\circ} \mathrm{C}$ operating temperature.

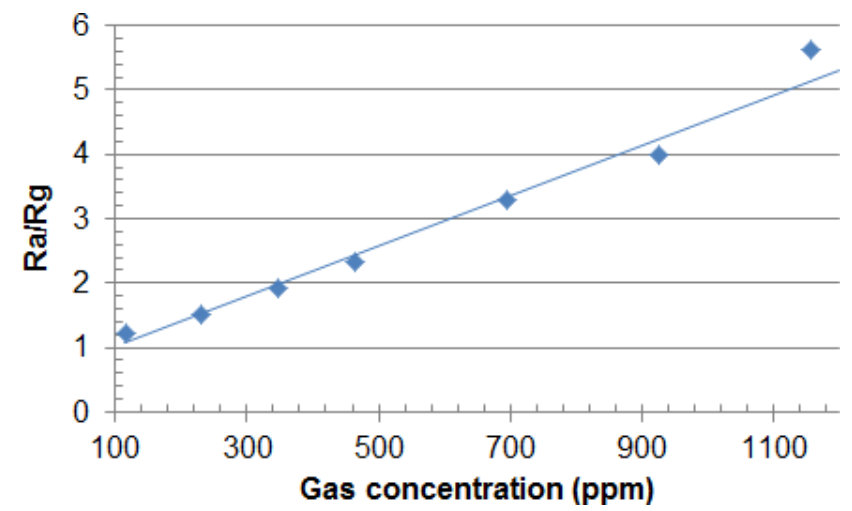

Figure 8. Dependence of the response of $\mathrm{MWCNTs} / \mathrm{SnO}_{2} \mathrm{FA}$ vapor sensor on gas concentration measured at $200{ }^{\circ} \mathrm{C}$ operating temperature.

\subsection{On possible mechanisms of gas sensitivity}

It is known that attachment of carboxyl groups on the surface of MWCNTs is useful in nucleation and trapping of other materials including tin-oxide nanoparticles. Earlier it was shown that $\mathrm{COOH}$ groups, attached on the surface of MWCNTs, have strong interactions with alcohol vapors, which result due to the formation of hydrogen bonds between $\mathrm{COOH}$ groups and $\mathrm{OH}$ groups of alcohol molecules (Aroutiounian et al., 2013; Adamyan et al., 2016). This hydrogen bond should be removed by increasing the temperature, which contributes to long recovery times in MWCNTs/ $\mathrm{SnO}_{2}$ sensors.

The higher operating temperature of the gas response is observed up to the temperature at which the response achieves to its maximal value. With the subsequent increase in operating temperature, desorption of chemisorbed oxygen ions takes place, and the gas response decreases. The recovery times are decreasing.

When there is relatively more content of $\mathrm{SnO}_{2}$ in a nanocomposite, as in our case, MWCNT nanochannels play a

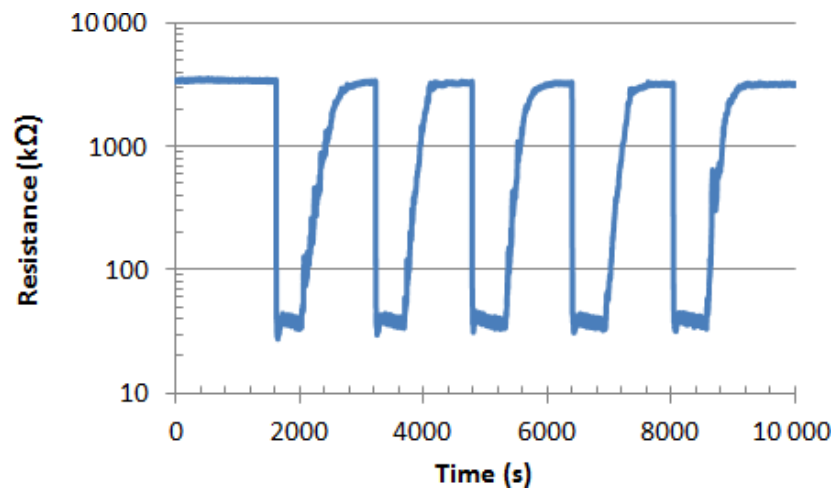

Figure 9. The electrical resistance change in $\mathrm{MWCNTs} / \mathrm{SnO}_{2}$ thick-film PG sensors vs. time measured upon cyclic exposure of $650 \mathrm{ppm}$ PG vapors in air at $200^{\circ} \mathrm{C}$ operating temperature.

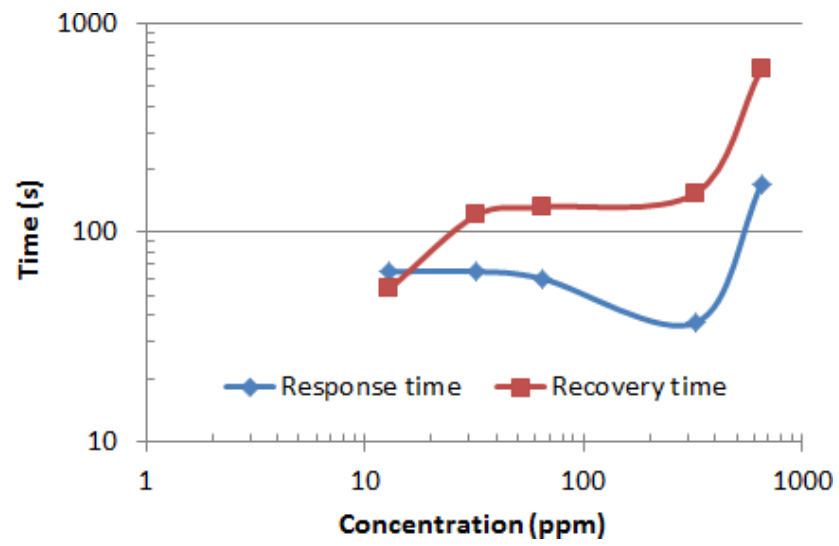

Figure 10. Dependence of response and recovery times of MWCNTs/SnO 2 PG vapor sensor on gas concentration measured at $200^{\circ} \mathrm{C}$ operating temperature.

smaller role since nanotubes are entirely closed by plenty of $\mathrm{SnO}_{2}$ nanoparticles. Accessibility of gas-molecule penetration to MWCNT nanochannels through the metal-oxide thick film is very difficult. Therefore the response is mainly determined by the number of metal-oxide nanoparticles and a considerable amount of surface adsorption sites. MWCNTs only prevent the formation of $\mathrm{SnO}_{2}$ agglomerates and thereby ensure the developed surface, due to repulsive forces between the carboxyl groups adsorbed on it.

The oxidation reaction of PG and DMF vapors on the nanocomposite surface could be represented as follows, respectively:

$\mathrm{C}_{3} \mathrm{H}_{8} \mathrm{O}_{2}(\mathrm{~g})+8 \mathrm{O}^{-} \rightarrow 3 \mathrm{CO}_{2}(\mathrm{~g})+4 \mathrm{H}_{2} \mathrm{O}(\mathrm{g})+8 e^{-}$

and

$$
\begin{aligned}
4 \mathrm{C}_{3} \mathrm{H}_{7} \mathrm{NO}(\mathrm{g})+42 \mathrm{O}^{-} & \rightarrow 12 \mathrm{CO}_{2}(\mathrm{~g})+4 \mathrm{NO}_{2}(\mathrm{~g}) \\
& +14 \mathrm{H}_{2} \mathrm{O}(\mathrm{g})+42 e^{-} .
\end{aligned}
$$

At the temperature corresponding to the highest response, the reactivity of the target gas molecules is proportional to the 


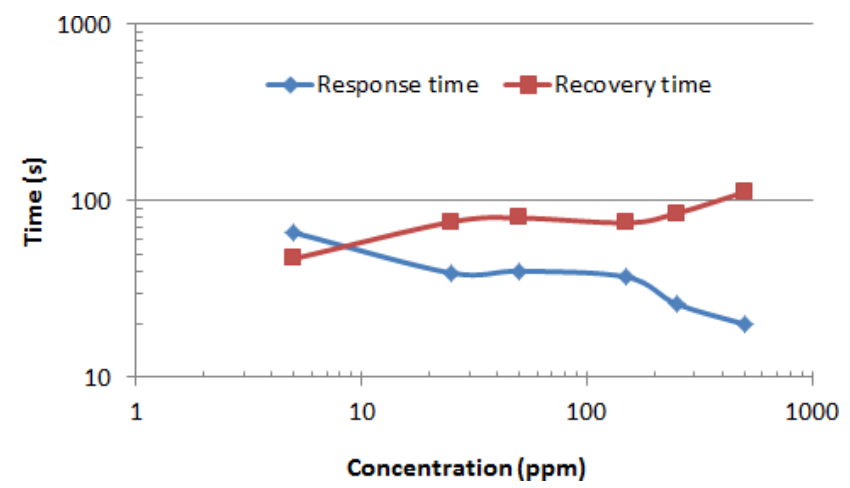

Figure 11. Dependence of response and recovery times of MWCNTs $/ \mathrm{SnO}_{2}$ DMF vapor sensor on gas concentration measured at $200^{\circ} \mathrm{C}$ operating temperature.

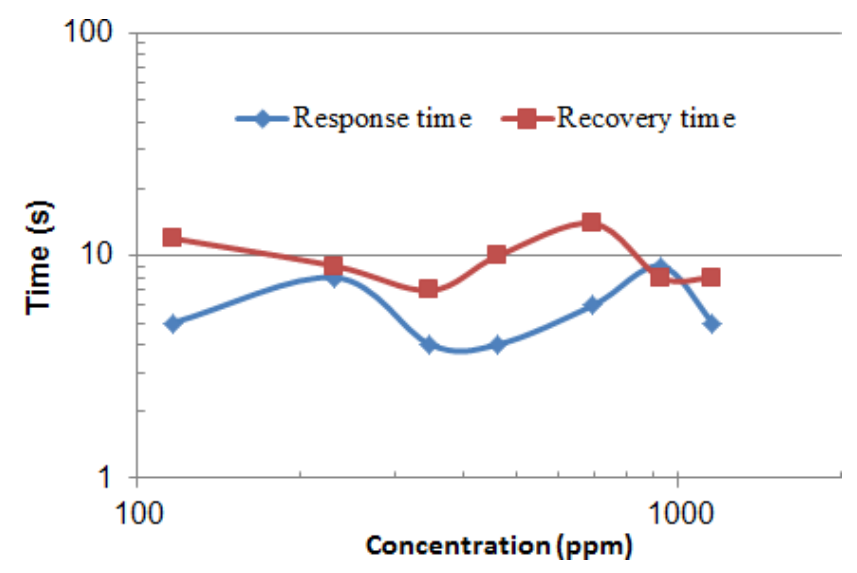

Figure 12. Dependence of response and recovery times of MWCNTs $/ \mathrm{SnO}_{2} \mathrm{FA}$ vapor sensor on gas concentration measured at $200^{\circ} \mathrm{C}$ operating temperature.

speed of diffusion into the sensing layer. Hence, the target gas has the chance to penetrate sufficiently into the sensing layer and react with an appropriate speed. The competition between the amount of adsorbed target gases and their oxidation rate supports the maximum response and its sharp decline. With the resulting increase in operating temperature, desorption of the adsorbed oxygen ions from the surface of the sensor is growing. It follows that at higher operating temperatures, fewer oxygen ions are present on the surface of $\mathrm{SnO}_{2}$, which might be taking part in reaction to target gases. Therefore the response falls at high operating temperatures. Moreover, the temperature has an impact on the physical properties of the semiconducting sensor material. To demonstrate, at higher temperatures the carrier concentration increases (owing to releasing electrons back to the conduction band in consequence of desorption of adsorbed oxygen) and the Debye length decreases. This, in turn, may be one of the possible reasons for the rise in $R_{\mathrm{g}}$ curve in Fig. 3, which leads to the decrease in response at higher temperatures.

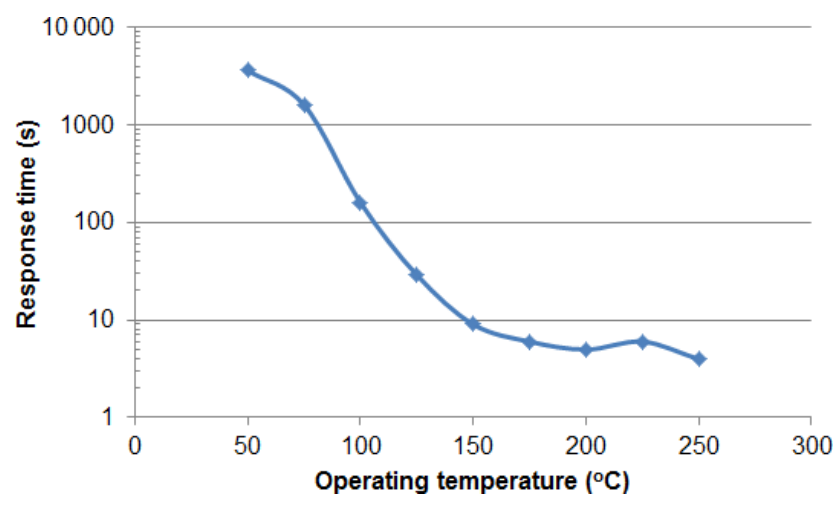

Figure 13. Dependence of the response time of $\mathrm{MWCNTs} / \mathrm{SnO}_{2}$ PG vapor sensor on operating temperature.

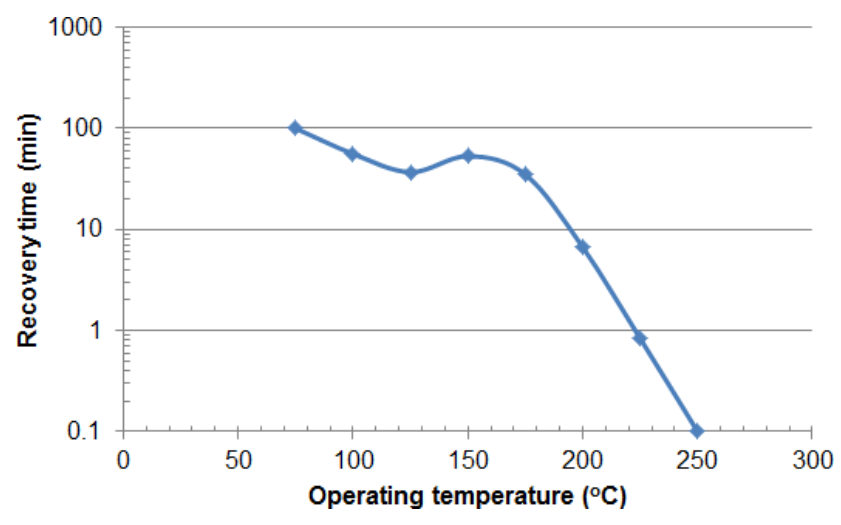

Figure 14. Dependence of the recovery time of MWCNTs $/ \mathrm{SnO}_{2}$ PG vapor sensor on operating temperature.

Although the molecular weight of both considered target gases are close to each other, the quantity of carbon atoms is just the same. Response from DMF-vapor exposure is smaller because the adsorbed oxygen ions demand the full oxidation reaction. Therefore a chemical decomposition occurs. Nevertheless, the $1: 200$ weight ratios of the nanocomposite sensor components, with the relatively large amount of $\mathrm{SnO}_{2}$ particles, promote an initiation of the sufficiently large quantity of ionized adsorption centers which, in turn, ensures a relatively high response to DMF gas exposure.

At exposure to low concentrations of both PG and DMF gases, recovery times become shorter than response times (Figs. 5, 6). We explain this phenomenon by the fact that the chemisorption process is developing slower and on a larger scale than desorption of products, obtained in the course of the chemical reaction. That is due to the necessity of having many adsorption centers for implementation of the oxidation reaction, as well as because of desorption after the exposure by low concentrations of gases, which takes place from the relatively shallow depth of the near-surface layer. Moreover, the loose structure of the sensitive thick film is obtained because of the presence of carbon nanotubes in the nanocom- 


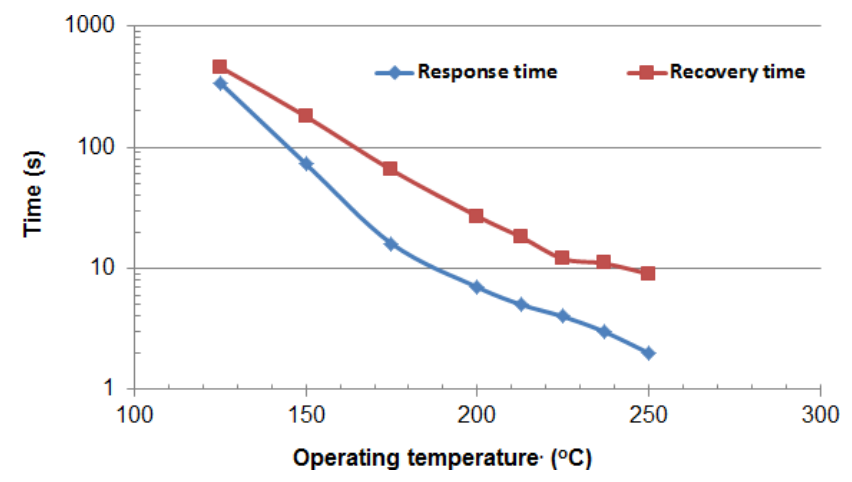

Figure 15. Dependence of the response and recovery times of MWCNTs/SnO 2 FA vapor sensor on operating temperature.

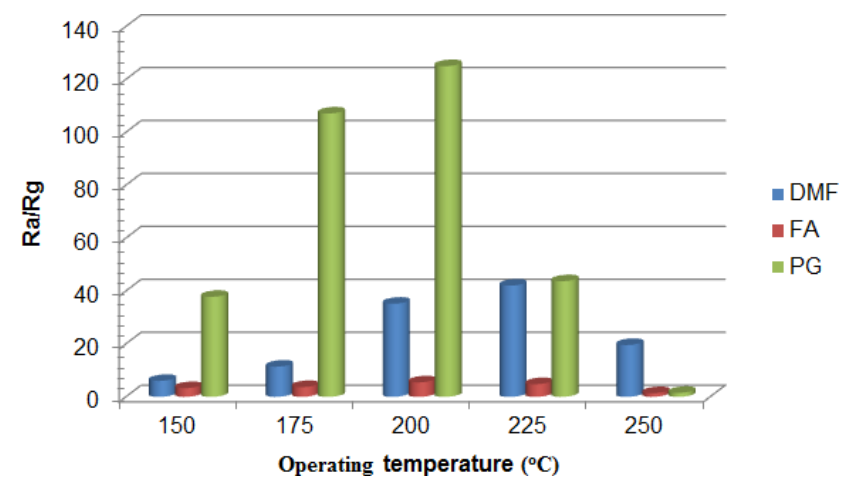

Figure 16. Comparison of responses of MWCNTs $/ \mathrm{SnO}_{2}$ sensors to $650 \mathrm{ppm}$ PG, $500 \mathrm{ppm}$ DMF and $1160 \mathrm{ppm}$ FA vapor exposure at various operating temperatures.

posite facilitates and outlet gaseous products formed by the reaction that leads to a decrease in recovery times.

At the high-impact gas concentrations, after filling adjacent to the surface adsorption sites the remaining target gas molecules, only after overcoming of $\mathrm{SnO}_{2}$ clusters by diffusion and penetrating more rooted in the nanocomposite layer, are adsorbed there. This leads to an increase in response time. The same factors affect the rise in recovery time too.

As Fig. 10 shows, the response and recovery times are highly dependent on the concentration of propylene glycol. Why do response and recovery times rise with an increase in concentrations of propylene glycol?

As we pointed out above, propylene glycol in the gas phase is obtained by vaporization of the liquid, dripping it on the heated metal plate or by using the temperature resistor (coil). The issue is that a large amount of the liquid will vaporize if heat transfer occurs very quickly. When it is heated slowly, a portion of PG vapors is lost, condenses or absorbs on the chamber walls or in other places. Rapid heating is necessary for other areas, as having a small amount of heat in a confined space of the measurement chamber and, above all, for ensuring the possibility of the sensor firm performance determination. Moreover, very high-temperature heat source provides plenty of oxygen compared with a liquid state (Walter Jr. et al., 1985). This promotes that at least part of the liquid can attain ignition temperature by heating (flash temperature is only just $64^{\circ} \mathrm{C}$ ) instead of plain vaporization. When combustion is complete, and there is plenty of oxygen pieces, as in this case, the chemisorption reaction happens according to Eq. (1) with formation just enough volatile $\mathrm{CO}_{2}$ and water to release the conduction electrons. If the combustion is incomplete and there is not enough oxygen, intermediate formaldehyde is formed along with the most thermodynamically stable $\mathrm{CO}_{2}$ and water (Jensen et al., 2015). The oxidation of PG to formaldehyde $\left(\mathrm{CH}_{2} \mathrm{O}\right)$ happens as follows:

$$
\begin{aligned}
\mathrm{CH}_{2} \mathrm{OH}-\mathrm{CHOH}-\mathrm{CH}_{3}+4 \mathrm{O}^{-} & \rightarrow 2 \mathrm{CH}_{2} \mathrm{O}+2 \mathrm{H}_{2} \mathrm{O} \\
& +\mathrm{CO}_{2}+4 e^{-} .
\end{aligned}
$$

In this case, we explain the sharp rise in PG response and recovery times at high PG vapor concentrations (beginning from about $300 \mathrm{ppm}$ and higher) by intermediate formaldehyde formation. It is known that formaldehyde molecules are more stable than PG, but less stable than carbon dioxide (Ertl and Tornau, 1977). So, decomposition of formaldehyde at high temperatures but below $300^{\circ} \mathrm{C}$ occurs very slowly (rate of decomposition is about $0.44 \%$ per minute). The main products of the decomposition are carbon monoxide and hydrogen. We suppose that at least part of the formaldehyde gas molecules is adsorbed on the Ru catalyst. Based on the data of works (Ertl and Tornau, 1977; Vannice, 1975; Borowiecki and Barcicki, 1979) where decomposition of formaldehyde on Pt, Pd and Ru has been studied, we can assume that the catalytic decomposition of formaldehyde in our case on ruthenium also occurs as follows:

$$
\mathrm{CH}_{2} \mathrm{O}_{\text {gas }} \rightarrow \mathrm{CH}_{2} \mathrm{O}_{\text {ads }} \rightarrow \underset{\text { | }}{\mathrm{Hu}} \stackrel{\mathrm{Ru}}{\mathrm{C} \cdots \cdot \mathrm{Hu}} \rightarrow \mathrm{H}_{2 \text { gas }}+\mathrm{CO}_{\text {gas }}
$$

Here, the dotted lines indicate the weak attraction. Oppositely charged adsorbed molecules of hydrogen and carbon monoxide are reacted in the adsorption layer. The primary product of this interaction can be adsorption complex of formaldehyde. The formation of such complexes occurs at low speed and goes with a decrease in the work function (Vlasenko and Yuzefovich, 1969). In the presence of carbon monoxide and carbon dioxide gases under hydrogenation simultaneously, these gases are competing for active adsorption centers. Since the carbon monoxide molecules will interact with active sites faster, the hydrogenation of $\mathrm{CO}$ occurs, but not as carbon dioxide (Vlasenko and Yuzefovich, 1969). According Ertl and Tornau (1977) the process for carbon dioxide, in this case, occurs sufficiently slowly. The time of formaldehyde decomposition at high concentrations of PG 
is close based on the order of magnitude to the response and recovery times demonstrated in the Figures. At that, more concentrations of PG and more parts of formaldehyde are involved in Eq. (3) as more extended response and recovery times of the sensor. The dominant contribution of the adsorption of formaldehyde or incomplete combustion with an increase in PG concentration is started, apparently, with about $300 \mathrm{ppm}$. Following Ertl and Tornau (1977), the presence of $\mathrm{CO}$ and its attractive interaction with $\mathrm{H}_{2}$ causes a lowering of hydrogen adsorption energy and an increase in $\mathrm{H}_{2}$ desorption energy, respectively. At lower concentrations of PG, the proportion of adsorbed complex of formaldehyde is negligible, and both response and recovery times are relatively short and defined by the speed of chemisorption and desorption of the Eq. (1) products. As mentioned, the amount of response and recovery times differs based on DMF vapor concentrations (Fig. 11). Smaller gas concentrations require less recovery time than the response time. Practically, in the whole studied concentrations range, with the rise of gas concentration, the response time is decreasing whereas recovery time is increasing.

\section{Conclusion}

In this paper, we have investigated ruthenated MWCNTs $/ \mathrm{SnO}_{2}$ thick-film nanocomposite sensors using hydrothermal synthesis and sol-gel technologies. It is revealed that sensors give a sufficiently high response to such harmful and hazardous gases as PG, DMF and FA at relatively low operating temperatures. The fast response of the sensors (on the order of seconds) and acceptable recovery times are observed under all gas concentrations influence at $200^{\circ} \mathrm{C}$ operating temperature. The minimal PG, DMF and FA gas concentrations at which the perceptible signal is registered are 13, 5 and $115 \mathrm{ppm}$, respectively. Due to the linear dependence of the response on the concentration of PG, DMF and FA vapors, it is possible to measure the concentration of mentioned gases in the atmosphere quickly.

Data availability. No data sets were used in this article.

Competing interests. The authors declare that they have no conflict of interest.

Special issue statement. This article is part of the special issue "Sensor/IRS2 2017". It is a result of the AMA Conferences, Nuremberg, Germany, 30 May-1 June 2017.

Acknowledgements. This work was supported by NATO EAP SFPP 984.597.
Edited by: Peter A. Lieberzeit

Reviewed by: two anonymous referees

\section{References}

Adamyan, A. Z., Adamyan, Z. N., and Aroutiounian, V. M.: Preparation of $\mathrm{SnO}_{2}$ films with thermally stable nanoparticles, Sensors, 3, 438-442, https://doi.org/10.3390/s31000438, 2003.

Adamyan, A. Z., Adamyan, Z. N., Aroutiounian, V. M., Arakelyan, A. H., Turner, J., and Touryan, K.: Sol-gel derived thin-film semiconductor hydrogen gas sensor, Int. J. Hydrogen. Energ., 32, 4101-4108, https://doi.org/10.1016/j.ijhydene.2007.03.043, 2007.

Adamyan, Z. N., Sayunts, A. G., Khachaturyan, E. A., and Aroutiounian, V. M.: Study of nanocomposite thick-film butanol vapor sensors, J. Contemp. Phys.-Arme+, 51, 143-149, https://doi.org/10.3103/S1068337216020067, 2016.

Adamyan, Z. N., Sayunts, A. G., Aroutiounian, V. M., Khachaturyan, E. A., Adamyan, A. Z., Vrnata, M., Fitl, P., and Vlček, J.: MWCNTs $/ \mathrm{SnO}_{2}$ Harmful Gas Sensors, in: Proceedings of the 18th International Conference on Sensors and Measurement Technology, Nierenberg, Germany, 30 May-1 June 2017, 708713, https://doi.org/10.5162/sensor2017/P5.5, 2017.

Arafat, M. M., Dinan, B., Akbar, S. A., and Haseeb, A. S. M. A.: Gas sensors based on one dimensional nanostructured metal-oxides: A Review, Sensors, 12, 7207-7258, https://doi.org/10.3390/s120607207, 2012.

Aroutiounian, V. M.: Metal oxide hydrogen, oxygen and carbon monoxide sensors for hydrogen setups and cells, Int. J. Hydrogen. Energ., 32, 1145-1158, https://doi.org/10.1016/j.ijhydene.2007.01.004, 2007.

Aroutiounian, V. M.: Gas sensors based on functionalized carbon nanotubes, J. Contemp. Phys.-Arme+, 50, 333-354, https://doi.org/10.3103/S1068337215040064, 2015.

Aroutiounian, V. M., Adamyan, A. Z., Khachaturyan, E. A., Adamyan, Z. N., Hernadi, K., Pallai, Z., Nemeth, Z., Forro, L., Magrez, A., and Horvath, E.: Study of the surface-ruthenated $\mathrm{SnO}_{2}$ /MWCNTs nanocomposite thickfilm gas sensors, Sensor. Actuat. B-Chem., 177, 308-315, https://doi.org/10.1016/j.snb.2012.10.106, 2013.

Aroutiounian, V. M., Adamyan, Z. N., Sayunts, A. G., Khachaturyan, E. A., Adamyan, A. Z., Hernadi, K., Nemeth, Z., and Berki, P.: Comparative study of VOC sensors based on ruthenated $\mathrm{MWCNT} / \mathrm{SnO}_{2}$ nanocomposites, Int. J. Emerging Trends Sci. Technol., 1, 1309-1319, https://doi.org/10.18535/ijetst, 2014.

Aroutiounian, V. M., Adamyan, Z. N., Sayunts, A. G., Khachaturyan, E. A., and Adamyan, A. Z.: Study of MWCNT/SnO nanocomposite acetone and toluene vapor sensors, in: Proceedings of the 17th International Conference on Sensors and Measurement Technology, Nierenberg, Germany, 19-21 May 2015, 836-841, https://doi.org/10.5162/sensor2015/P8.3, 2015.

Bai, X., Ji, H., Gao, P., Zhang, Y., and Sun, X.: Morphology, phase structure and acetone sensitive properties of copper-doped tungsten oxide sensors, Sensor. Actuat. B-Chem., 193, 100-106, https://doi.org/10.1016/j.snb.2013.11.059, 2014.

Borowiecki, T. and Barcicki, J.: Selectivity of the steam reforming of methane over metallic catalysts, React. Kinet. Catal. L., 12, 101-106, https://doi.org/10.1007/BF02071432, 1979. 
Chang, H. Y., Shih, T. S., Guo, Y. L., Tsai, C. Y., and Hsu, P. C.: Sperm function in workers exposed to N,N-dimethylformamide in the synthetic leather industry, Fertil. Steril., 81, 1589-1594, https://doi.org/10.1016/j.fertnstert.2003.10.033, 2004.

Chuang, W. Y., Yang, S. Y., Wu, W. J., and Lin, C. T.: A Room-Temperature Operation Formaldehyde Sensing Material Printed Using Blends of Reduced Graphene Oxide and Poly(methyl methacrylate), Sensors, 15, 28842-28853, https://doi.org/10.3390/s151128842, 2015.

Chung, F. C., Wu, R. J., and Cheng, F. C.: Fabrication of an $\mathrm{Au} @ \mathrm{SnO}_{2}$ core-shell structure for gaseous formaldehyde sensing at room temperature, Sensor. Actuat. B-Chem., 190, 1-7, https://doi.org/10.1016/j.snb.2013.08.037, 2014.

Couteau, E., Hernadi, K., Seo, J. W., Thien-Nga, L., Mikó, Cs., Gáal, R., and Forró, L.: CVD synthesis of high-purity multiwalled carbon nanotubes using $\mathrm{CaCO}_{3}$ catalyst support for large-scale production, Chem. Phys. Lett., 378, 9-17, https://doi.org/10.1016/S0009-2614(03)01218-1, 2003.

Ellenhorn, M. J., Schonwald, S., Ordog, G., and Wasserberger, J.: Ellenhorn's medical toxicology: diagnosis and treatment of human poisoning, 2nd edition, MD: Williams \& Wilkins, Baltimore, USA, 1675, 1997.

Ertl, G. and Tornau, J.: The catalytic decomposition of formaldehyde on palladium, Z. Phys. Chem. Neue. Fol., 104, 301-308, 1977.

Feyzabad, S. A., Khodadadia, A. A., Naseh, M. V., and Mortazavi, Y.: Highly sensitive and selective sensors to volatile organic compounds using MWCNTs/SnO 2 , Sensor. Actuat. B-Chem., 166167, 150-155, https://doi.org/10.1016/j.snb.2012.02.024, 2012.

Fine, G. F., Cavanagh, L. M., Afonja, A., and Binions, R.: Metal oxide semi-conductor gas sensors in environmental monitoring, Sensors, 10, 5469-5502, https://doi.org/10.3390/s100605469, 2010.

Fiorito, A., Larese, F., Molinari, S., and Zanin, T.: Liver function alterations in synthetic leather workers exposed to dimethylformamide, Am. J. Ind. Med., 32, 255-260, https://doi.org/10.1002/(SICI)10970274(199709)32:3<255::AID-AJIM11>3.0.CO;2-U, 1997.

Flueckiger, J., Ko, F. K., and Cheung, K. C.: Microfabricated Formaldehyde Gas Sensors, Sensors, 9, 9196-9215, https://doi.org/10.3390/s91109196, 2009.

Hieu, N. V., Thuy, L. T. B., and Chien, N. D.: Highly sensitive thin film $\mathrm{NH}_{3}$ gas sensor operating at room temperature based on $\mathrm{SnO}_{2}$ /MWCNTs composite, Sensor. Actuat. B-Chem., 129, 888-895, https://doi.org/10.1016/j.snb.2007.09.088, 2008.

Jensen, R. P., Luo, W., Pankow, J. F., Strongin, R. M., and Peyton, D. H.: Hidden Formaldehyde in E-Cigarette Aerosols, New Engl. J. Med., 372, 392-394, https://doi.org/10.1056/NEJMc1413069, 2015.

Korotcenkov, G., Han, S. D., Cho, B. K., and Brinzari, V.: Grain size effects in sensor response of nanostructured $\mathrm{SnO}_{2}$ and $\mathrm{In}_{2} \mathrm{O}_{3}$ based conductometric thin film gas sensor, Crit. Rev. Solid. State., 34, 1-17, https://doi.org/10.1080/10408430902815725, 2009.

Korotcenkov, G., Han, S. H., and Cho, B. K.: Material design for metal oxide chemiresistive gas sensors, J. Sensor Sci. Technol., 22, 1-17, https://doi.org/10.5369/JSST.2013.22.1.1, 2013.

Lefebvre, M. A., Meulingb, W. J., Engel, R., Coroamac, M. C., Rennerc, G., Pape, W., and Nohynek, G. J.: Consumer in- halation exposure to formaldehyde from the use of personal care products/cosmetics, Regul. Toxicol. Pharm., 63, 171-176, https://doi.org/10.1016/j.yrtph.2012.02.011, 2012.

Li, X., Li, X., Wang, J., and Lin, S.: Highly sensitive and selective room-temperature formaldehyde sensors using hollow $\mathrm{TiO}_{2}$ microspheres, Sensor. Actuat. B-Chem., 219, 158-163, https://doi.org/10.1016/j.snb.2015.05.031, 2015.

Magrez, A., Seo, J. W., Smajda, R., Mionić, M., and Forró, L.: Catalytic CVD Synthesis of Carbon Nanotubes: Towards High Yield and Low Temperature Growth, Materials, 3, 4871-4891, https://doi.org/10.3390/ma3114871, 2010.

Malaguarnera, G., Cataudella, E., Giordano, M., Nunnari, G., Chisari, G., and Malaguarnera, M.: Toxic hepatitis in occupational exposure to solvents, World. J. Gastroentero., 18, 2756-2766, https://doi.org/10.3748/wjg.v18.i22.2756, 2012.

Nemeth, Z., Pallai, Z., Reti, B., Balogh, Z., Berkesi, O., Baan, K., Erdohelyi, A., Horvath, E., Veréb, G., Dombi, A., Forró, L., and Hernadi, K.: Synthesis, Comparative Characterization and Photocatalytic Application of $\mathrm{SnO}_{2}$ /MWCNT Nanocomposite Materials, J. Coating Sci. Technol., 1, 137-150, 2014 a.

Nemeth, Z., Reti, B., Pallai, Z., Berki, P., Major, J., Horvath, E., Magrez, A., Forro, L., and Hernadi, K.: Chemical challenges during the synthesis of MWCNT-based inorganic nanocomposite materials, Phys. Status. Solidi. B., 251, 2360-2365, https://doi.org/10.1002/pssb.201451141, 2014b.

Park, H. J., Choi, N. J., Kang, H., Jung, M. Y., Park, J. W., Park, K. H., and Lee, D. S.: A ppb-level formaldehyde gas sensor based on $\mathrm{CuO}$ nanocubes prepared using a polyol process, Sensor. Actuat. B-Chem., 203, 282-288, https://doi.org/10.1016/j.snb.2014.06.118, 2014.

Robertson, O. H., Loosli, C. G., and Puck, T. T.: Test for chronic toxicity of propylene glycol and triethylene glycol on monkeys and rats by vapor inhalation and oral administration, J. Pharmacol. Exp. Ther., 91, 52-76, 1947.

Salthammer, T., Mentese, S., and Marutzky, R.: Formaldehyde in the indoor environment, Chem. Rev., 110, 2536-2572, https://doi.org/10.1021/cr800399g, 2010.

Shankar, P., Bosco, J., and Rayappan, B.: Gas sensing mechanism of metal oxides: The role of ambient atmosphere, type of semiconductor and gases - A review, Sci. Lett., 4, 1-18, 2015.

Vannice, M. A.: The catalytic synthesis of hydrocarbons from $\mathrm{H}_{2} \mathrm{CO}$ mixtures over the group VIII metals: II. The kinetics of the methanation reaction over supported metals, J. Catal., 37, 462473, https://doi.org/10.1016/0021-9517(75)90182-7, 1975.

Vlasenko, V. M. and Yuzefovich, G. E.: Mechanism of the Catalytic Hydrogenation of Oxides of Carbon to Methane, Russ. Chem. Rev., 38, 728-739, https://doi.org/10.1070/RC1969v038n09ABEH001829, 1969.

Walter Jr., J. R., McClure, G., Brown, P. W., and Galuk, K. G.: An investigation of the degradation of aqueous ethylene glycol and propylene glycol solutions using ion chromatography, Sol. Energ. Mater., 11, 455-467, https://doi.org/10.1016/01651633(85)90016-4, 1985.

Xu, C., Tamaki, J., Miura, N., and Yamazoe, N.: Grain size effects on gas sensitivity of porous $\mathrm{SnO}_{2}$-based elements, Sensor. Actuat. B-Chem., 3, 147-155, https://doi.org/10.1016/09254005(91)80207-Z, 1991.

Xu, K., Zeng, D., Tian, S., Zhang, S., and Xie, C.: Hierarchical porous $\mathrm{SnO}_{2}$ micro-rods topologically trans- 
ferred from tin oxalate for fast response sensors to trace formaldehyde, Sensor. Actuat. B-Chem., 190, 585-592, https://doi.org/10.1016/j.snb.2013.09.021, 2014. 